\title{
Direct Measurement of Free Radical Levels in the Brain After Cortical Ischemia Induced by Photothrombosis
}

\author{
J. MARES ${ }^{1}$, K. NOHEJLOVA ${ }^{1}$, P. STOPKA $^{2}$, R. ROKYTA ${ }^{1}$ \\ ${ }^{1}$ Department of Normal Pathological and Clinical Physiology, Third Faculty of Medicine, Charles \\ University, Czech Republic, ${ }^{2}$ Institute of Inorganic Chemistry of the Czech Academy of Sciences, \\ Řež u Prahy, Czech Republic
}

Received July 3, 2015

Accepted April 1, 2016

On-line July 15, 2016

\section{Summary}

Tissue ischemia is connected with the production of free radicals (FR). This study was designed to directly measure of the amount of $F R$ in rat brains related to a photothrombotic ischemic event shortly after establishing the lesion. A model of left hemisphere photothrombosis ischemia was used in the experiment. Brains of animals from the experimental group were removed and placed in liquid $\mathrm{N}_{2}$ for 60 min after the green laser exposure, the control group brains, exposed to the photosensitive dye Rose Bengal (RB), were placed in liquid $\mathrm{N}_{2}$ for 80 min after RB application, naïve control brains were also briefly stored in liquid $N_{2}$. Spectroscopy of electron paramagnetic (spin) resonance was used to directly measure FR (hydroxyl $\left(\mathrm{OH}^{*}\right)$ and nitroxyl (NO*). Compared to naïve controls, both the ischemia and RB groups had significantly higher levels of $\mathrm{OH}^{\circ}$, however, there were no differences between them. Comparison of hemispheres, i.e. with and without ischemia, in the experimental group did not show any significant difference in $\mathrm{OH}^{\bullet}$. NO ${ }^{\bullet}$ were elevated in the ischemia and RB groups compare to naïve controls. Higher levels of NO were found in hemispheres with ischemia compared to unexposed hemispheres. Increases in $\mathrm{OH}^{\bullet}$ were probably associated with the action of RB itself in this model of ischemia. Increases in $\mathrm{NO}^{*}$ were closely related to the pathogenesis of photothrombotic ischemia and could be related to the activity of nitric oxide synthases.

\section{Key words}

Free radicals • EPR • Focal ischemia • Brain • Photothrombosis

\section{Corresponding author}

K. Nohejlova, Department of Normal Pathological and Clinical
Physiology, Third Faculty of Medicine, Charles University, Ke Karlovu 4, 12000 Prague, Czech Republic. Fax: +420 224923 827. E-mail: k.deykun@gmail.com

\section{Introduction}

Changes in the oxygen supply of the brain activate blood flow regulation systems that maintain delivery of energy sources that sustain brain activities. Activation of similar compensatory mechanisms to ensure neuronal survival can be found among different pathological conditions, e.g. head trauma, cerebral edema, and intracranial hypertension (Uchino et al. 2008). Focal ischemic lesions of the brain have both local and generalized effects, which include changes in perfusion and, as a consequence, changes in biological oxidation of tissue due to oxygen deficiency. Such processes, including partial reperfusion, can lead to the initiation of oxidative stress (Hung et al. 2014, Watson et al. 2002). Once the lack of oxygen induces necrosis, tissue damage is aggravated by inflammatory reactions (Lapi and Colantuoni 2015). The ischemic state is often followed by partial reperfusion of the affected tissue through activation of anastomotic collateral vessels (Lapi and Colantuoni 2015). Changes in blood flow may also be associated with the signaling function of reactive oxygen species (ROS) and free radicals (FR) (Schoknecht et al. 2014, Valko et al. 2007).

Photo-chemically induced thrombosis (photothrombosis) of cerebral vessels caused by production of singlet oxygen in laser irradiated areas is 
a commonly used model of ischemic lesions in the cerebral cortex (Deykun et al. 2011, Watson et al. 1985, Watson et al. 2002). Using this model, a laser beam focused on the area of interest facilitates the formation of diffuse embolization of smaller vessels or even an obstruction of a large vessel. Development of ischemic lesions after photothrombosis also includes moderate vasoconstriction (Armstead et al. 2010). Thus, subsequent reactive vasodilatation and the above mentioned activation of anastomoses may contribute to a partial restoration of blood flow. In this model of focal ischemia, reperfusion related to vasodilatation is facilitated after subsequent stimulation using ultraviolet light (UV; $355 \mathrm{~nm}$ ) (Watson et al. 2002). Both lesion induction and reperfusion lead to the formation of singlet oxygen, NO, peroxynitrite, and hydroxyl radicals (Choi et al. 2007, Jimenez-Altayo et al. 2009).

Generation of FR in ischemic lesions can be determined by detection and measurement of FR products (De Filippis et al. 2015). In the present study the aim was to measure levels of FR directly in brain tissue, shortly after induction of ischemia, using electron paramagnetic (Spin) Resonance Spectroscopy (EPR/ESR). In this experiment, two FR were measured: hydroxyl $\left(\mathrm{OH}^{\bullet}\right)$ and nitroxyl $\left(\mathrm{NO}^{\bullet}\right)$ radicals. We hypothesized that after superficial unilateral ischemia, which was limited to the cortex, the level of FR increase throughout the brain. We were also interested to see if early changes of blood flow in the hemisphere contralateral to ischemic lesion (diaschisis) (Bidmon et al. 1998) could affect generation of free radicals on the contralateral non-ischemic side of the brain. Therefore, we split the brains with unilateral ischemic lesions into individual hemispheres and compared levels of FR between the hemispheres.

\section{Methods}

All procedures were performed in accordance with the Ethical Guidelines of the Third Faculty of Medicine, Charles University, Prague, Czech Republic and in accordance with the Guidelines of the Animal Protection Law of the Czech Republic, which corresponds to the respective EU regulations. Special care was taken to minimize animal suffering.

\section{Animals and reagents}

Young adult, male Wistar rats (ANLAB, Czech Republic), 180-210 g, were used in the experiments. Animals were housed 4 per cage in a temperature- controlled $\left(22-24^{\circ} \mathrm{C}\right)$ colony room, on a $12 \mathrm{~h}$ (light): $12 \mathrm{~h}$ (dark) cycle with lights on at 06:00 a.m., with free access to food and water. The rats were divided into one experimental and two control groups. Experimental group: (1) ischemia - Isch $(n=8)$, photothrombosis was used to create unilateral ischemic lesions in the brain cortex. Control groups: a) sham operated with photosensitive dye administration but without laser irradiation - RB $(n=8)$; b) naïve control $-C(n=9)$.

For technical reasons described later, 2 extra animals were subjected to ischemia and then used in a morphological evaluation to confirm the presence of superficial ischemic lesions.

All reagents used in the study were purchased from Sigma-Aldrich ${ }^{\circledR}$ Inc., Czech Republic.

\section{Induction of ischemia}

All procedures were performed on animals that were deeply anesthetized with ketamine $100 \mathrm{mg} / \mathrm{kg}$ i.p. (intraperitoneal) and xylazine $16 \mathrm{mg} / \mathrm{kg}$ i.m. (intramuscular).

Ischemia was induced by activation of the photosensitive dye, Rose Bengal - 4,5,6,7-Tetrachloro$2^{\prime}, 4^{\prime}, 5^{\prime}, 7^{\prime}$-tetra-iodofluorescein disodium salt, $20 \mathrm{mg} / \mathrm{ml} / \mathrm{kg}$ in $0.9 \% \mathrm{NaCl}$ solution, which was injected intravenously. The procedure was as follows: Soft tissues, skin and galea aponeurotica, were laid back from the skulls revealing the target area for irradiation. Rose Bengal solution was injected into the tail vein 2 min before initiation of laser irradiation. Activation of RB was done through an intact skull with a beam from a highpowered green-light laser (wave length $562 \mathrm{~nm}$; power density $=50 \mathrm{~mW} / \mathrm{mm}^{2}$; illuminated area $<1 \mathrm{~mm}^{2}$ ). The laser beam was sequentially centered on three points (6 min each, i.e. total duration of irradiation - $18 \mathrm{~min}$ ) of the left side of the skull. Anteroposterior (AP) and lateral (L) coordinates (bregma coordinates were AP: 0; L: $0 \mathrm{~mm}$ ) of the individual points were: A) AP: 0; L: $5.0 \mathrm{~mm}$; B) AP: - 0.5; L: $4.1 \mathrm{~mm}$ and C) AP: 0.5, L: $4.1 \mathrm{~mm}$ (Fig. 1 A; details - Deykun et al. (2011)). Total elapsed time from application of $\mathrm{RB}$ to the end of ischemia induction was $20 \mathrm{~min}$.

After the end of laser irradiation, the scalps were sutured closed. The animals, still anesthetized, were placed in individual cages for $60 \mathrm{~min}$. Then they were decapitated and their brains were removed. The brains of animals subjected to ischemia were divided into left (Isch-L), subjected to ischemia, and right, contralateral to ischemia (CL Isch-R), hemispheres. Thereafter brains 
were weighted, homogenized with spin trap DMPO (100 $\mu \mathrm{g}$ per brain) and briefly stored in liquid nitrogen until FR measurement.

The RB control group received intravenous Rose Bengal under general anesthesia, however, without any laser irradiation. $80 \mathrm{~min}$ after $\mathrm{RB}$ injection, the still anesthetized rats were decapitated. Naïve control animals were also anesthetized and decapitated.

Direct measurement of FR using Electron Paramagnetic (Spin) Resonance Spectroscopy

For direct measurement of hydroxyl and nitroxyl radicals we used of electron paramagnetic (spin) resonance (EPR/ESR) spectroscopy. The method has been described in detail in our previous studies (Rokyta et al. 2008, Mares et al. 2013). Briefly, tissue measurement of FR levels using EPR/EPS is based on the ability of certain chemicals to absorb microwave energy in strong magnetic fields. In this experiment, the spectra were recorded using an Elexsys E-540 Bruker-Biospin (Rheinstetten, Germany) EPR spectrometer, magnetic fields were measured with a $1 \mathrm{H}-\mathrm{NMR}$ magnetometer, and microwave frequencies were measured with a frequency counter. The spectra were later evaluated using the Bruker-Biospin EPR interface program. The results, after appropriate adjustments and standardization (for details refer to our previous study (Mares et al. 2013)), were presented in arbitrary units.

\section{Morphological evaluation of brain lesions}

Photochemical induction of ischemic lesions is well documented in previous works from our laboratory (Krysl et al. 2012, Matejovska et al. 2008). Nevertheless, 2 animals were used for morphological estimation of the stability of the method.
Twenty-four hours after induction of ischemia, anesthetized animals were perfused transcardially with cooled $0.9 \% \mathrm{NaCl}$ solution $\left(8-10^{\circ} \mathrm{C}\right)$. Immediately afterwards, animals were decapitated, the brains were removed and native photographs were taken. Then the brains were cut into coronal slices $(500 \mu \mathrm{m}$ thick) at the level of laser irradiation. The 2,3,5-triphenyltetrazolium chloride (2\% TTC, Sigma-Aldrich ${ }^{\circledR}$ Inc., Czech Republic) reduction test (Khan et al. 2000) was used to detect mitochondrial survival (Sun et al. 2014, Tao et al. 2013). Photographs of the slices were taken and evaluated for signs of ischemia.

TTC staining requires transcranial perfusion and sectioning of the brain. Therefore, experimental animals used for FR measurement could not be used.

\section{Statistical evaluation}

GraphPad Prism 6 (GraphPad Software, Inc., USA) was used for statistical evaluations. All results were tested for normality of distribution using the Kolmogorov-Smirnov test and the $\mathrm{F}$ test was used to compare variances.

EPR findings from the experimental group were compared with the control groups and evaluated using one-way ANOVA and Tukey's multiple comparison posttest. Findings within the experimental group (Isch-L vs. CL Isch-R) were compared using the paired t-test.

Results were accepted as significant when $\mathrm{p}<0.05$.

\section{Results}

The ischemic lesions were unilateral and limited to the cortex only, corresponding to the area of irradiation (Fig. 1B, C).

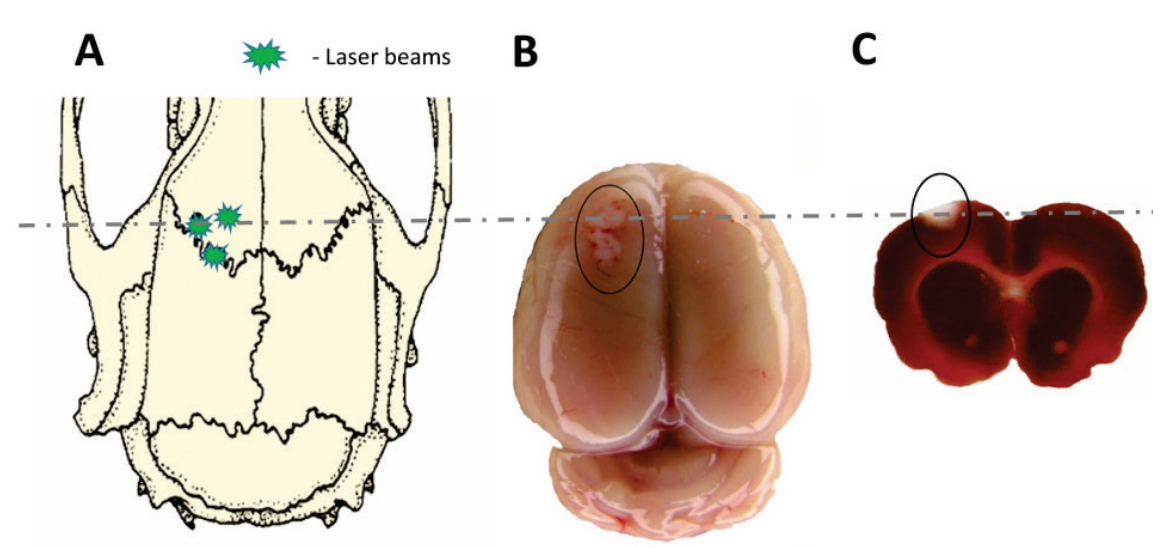

Fig. 1. (A) The locations of the irradiated points during an ischemia induction are marked by green asterisks. Anteroposterior and lateral coordinates (bregma $0 ; 0$ ): 1st point AP: 0; L: $5.0 \mathrm{~mm}$; 2nd point - AP: 0.5 ; L: $4.1 \mathrm{~mm}$ and 3rd point - AP: 0.5 , L: $4.1 \mathrm{~mm}$. Native photographs of the extracted brain (B) and the photo of brain slice dyed with TTC (C). The region of ischemic lesion is circled. 
A

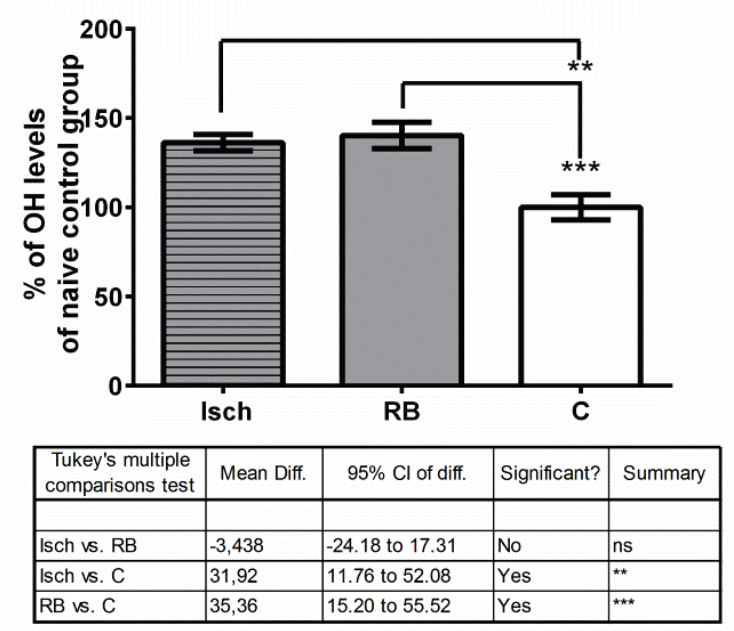

B

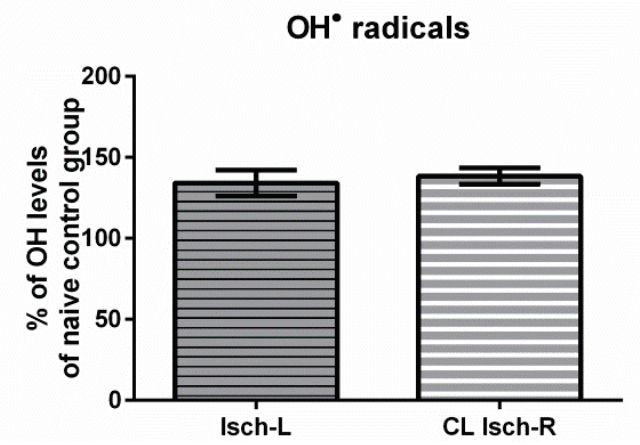

Fig. 2. Comparison of the number of hydroxyl radicals in brain tissue measured using the EPR/EPS method. (A) Data expressed in percentage of increase, when values of the control group were accepted as $100 \%$. The groups were assigned as follows: Isch - animals subjected to ischemia; $R B$ - control group received $i . v$. Rose Bengal with no surgical intervention; $C$ - naïve control group. Results of statistical analysis are presented in the table under the graph: one way ANOVA with Tukey's post-test (Isch vs. C as $* * \mathrm{p}<0.01$; RB vs. C as $* * * \mathrm{p}<0.001$ ). (B) Comparison of the number of hydroxyl radicals between the hemispheres in the group subjected to ischemia. Data expressed in percentage of increase, when values of the control group were accepted as $100 \%$. Ischemia subjected animals' hemispheres were divided as Isch- $L$ - left hemisphere subjected to ischemia and right hemisphere ( $C L$ Isch-R) contralateral to ischemia.

Measurement of hydroxyl radicals $\left(\mathrm{OH}^{\bullet}\right)$ using Electron Paramagnetic (Spin) Resonance Spectroscopy

Levels of hydroxyl radicals were significantly elevated in the ischemia and sham (RB) groups and compared to the naïve control group. The ischemia group had levels of $\mathrm{OH}^{\bullet}$ significantly higher relative to naïve controls: (one-way ANOVA $\mathrm{F}(2,22)=12.04, \mathrm{p}=0.0003$; Tukey's multiple comparison test: Isch vs. $\mathrm{C} p<0.01$; Fig. 2A). The RB group, sham operated with photosensitive dye administration, but without laser irradiation, also had increased levels of $\mathrm{OH}^{\bullet}$ compared to naïve controls: one-way ANOVA $\mathrm{F}(2,22)=12.04$,
A
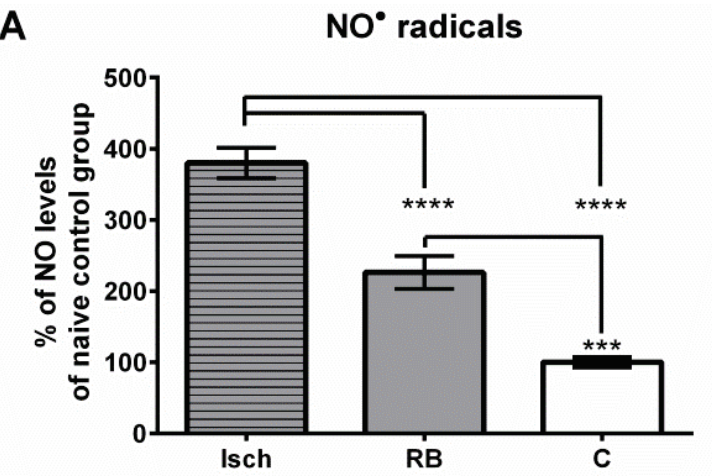

\begin{tabular}{|l|l|l|l|l|}
\hline $\begin{array}{c}\text { Tukey's multiple } \\
\text { comparisons test }\end{array}$ & Mean Diff. & 95\% Cl of diff. & Significant? & Summary \\
\hline & & & & \\
\hline Isch vs. RB & 182,5 & 106.1 to 258.9 & Yes & $* \star \star \star$ \\
\hline Isch vs. C & 332,1 & 257.9 to 406.3 & Yes & $* \star \star \star$ \\
\hline RB vs. C & 149,6 & 75.38 to 223.8 & Yes & $\star \star *$ \\
\hline
\end{tabular}

B

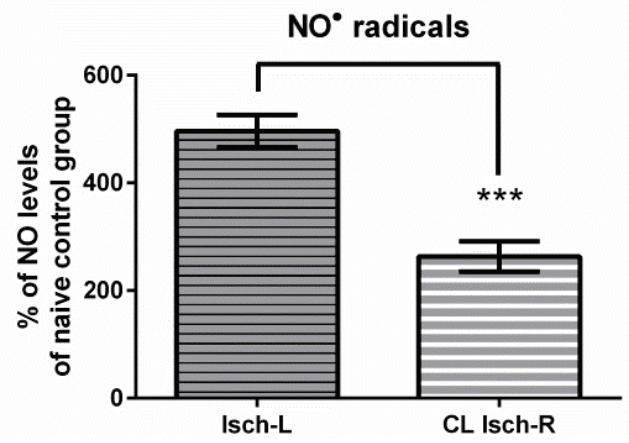

Fig. 3. Comparison of the number of nitroxyl radicals in brain tissue measured using the EPR/EPS method. (A) Data expressed in percentage of increase, when values of the control group were accepted as $100 \%$. The groups assigned as following: Isch animals subjected to ischemia; $R B$ - control group received i.v. Rose Bengal with no surgical intervention; $C$ - naïve control group. Results of statistical analysis are presented in the table under the graph: one way ANOVA with Tukey's post-test (RB vs. $\mathrm{C}$ as $* * * \mathrm{p}<0.001$, Isch vs. $\mathrm{C}$ and vs. RB as $* * * * \mathrm{p}<0.0001)$. (B) Comparison of the amount of nitroxyl radicals between the hemispheres in the group subjected to ischemia. Data expressed in percentage of increase, when values of control group were accepted as $100 \%$. Ischemia subjected animals' hemispheres were divided as Isch- $L$ - left hemisphere subjected to ischemia and right hemisphere ( $C L$ Isch- $R$ ) contralateral to ischemia. Asterisks present statistical analysis: paired t-test, $* * * \mathrm{p}<0.001$.

$\mathrm{p}=0.0003$; Tukey's multiple comparison test: $\mathrm{RB}$ vs. $\mathrm{C}$ $\mathrm{p}<0.001$; Fig. 2A). There were no significant differences in $\mathrm{OH}^{\bullet}$ levels between the ischemia and sham groups.

There were no differences in the level of $\mathrm{OH}^{\bullet}$ between affected and intact hemispheres in the Isch group (paired t-test; $\mathrm{p}=0.681$ - Fig. 2B).

Measurement of nitroxyl radicals $\left(N^{\bullet}\right)$ using Electron Paramagnetic (Spin) Resonance Spectroscopy

Nitroxyl radicals were also elevated in the ischemia and sham $(\mathrm{RB})$ groups relative to naïve control animals. The ischemia group had levels of $\mathrm{NO}^{\bullet}$ 
significantly higher compared to naïve controls: one-way ANOVA $\mathrm{F}(2,22)=63.22, \mathrm{p}<0.0001$; Tukey's multiple comparison test: Isch vs. $\mathrm{C} p<0.0001$; Fig. $3 \mathrm{~A}$. The sham (RB) group, sham operated with photosensitive dye administration, but without laser irradiation, also had increased levels of $\mathrm{NO}^{\bullet}$ compared to naïve controls: oneway ANOVA $\mathrm{F}(2,22)=63.22, \quad \mathrm{p}<0.0001 ; \quad$ Tukey's multiple comparison test: $\mathrm{RB}$ vs. $\mathrm{C} \mathrm{p}<0.001$; Fig. $3 \mathrm{~A}$ ). We also found significant differences between the ischemia and sham groups (Tukey's multiple comparison test: Isch vs. RB p $<0.0001-$ Fig. $3 \mathrm{~A}$ ).

Paired t-test analysis of nitroxyl radicals' levels between affected and intact hemispheres of Isch group confirmed significant differences: $\mathrm{p}=0.0006$ (Fig. 3B).

\section{Discussion}

Our study was aimed at understanding the early biochemical changes in the brain cortex after induction of a superficial ischemic lesion. To be specific we focused on the changes in free radicals created using the photothrombosis model of stroke and expected to find significant differences between the intact (contralateral) and affected hemispheres of the brain.

In the present study we observed that an ischemic insult, created using the photothrombosis animal model, caused a relatively rapid increase in the number of hydroxyl and nitroxyl radicals. In particular, the concentration of hydroxyl radicals increased in all intervention groups relative to naïve controls, but there was no difference between the experimental group (laser exposure) and the sham RB (without laser exposure) control group. Nitroxyl radicals, on the other hand, increased significantly in the hemisphere affected by ischemia compared to (i) the contralateral unaffected hemisphere, (ii) the brains of control animals that received Rose Bengal (without laser exposure), and (iii) naïve controls with no intervention. Changes in the number of hydroxyl and nitroxyl radicals were also observed in our previous experiment and during clinical evaluation of nociceptive and pain processes (Rokyta et al. 2008).

Free radicals (FR) have been implicated in a number of pathological conditions, including ischemia and reperfusion (Schoknecht et al. 2014, Siesjo 1981). Changes in tissue perfusion from hypoperfusion, i.e. oxygen deficit, to reperfusion, with the accompanying rapid increase in oxygen concentration, can induce generation of the primary FR - superoxide (Nelson et al.
1992), which then reacts with various tissue structures and leads to formation of other FRs. The first reaction is between superoxide and nitric oxide, which is mainly a compensatory reaction to tissue hypoperfusion. The result is generation of peroxynitrous acid, which spontaneously degrades forming hydroxyl radicals (Kontos 2001). Singlet oxygen also plays a very important role during these reactions (Holeček et al. 2007).

The hydroxyl radicals are very reactive oxygen species that have an extremely short half-life and small diffusion radius. Therefore, their transport from the ischemic area to the contralateral hemisphere via blood circulation is unlikely.

Photochemical induction of ischemia, through activation of Rose Bengal (RB) using a green light laser, initiates a local intravascular increase in the singlet oxygen concentration, which leads to endothelial lesions and intravascular coagulation. In the blood, RB is mainly transported bound to albumin (Forker and Luxon 1983). Activated Rose Bengal has been shown to initiate production of singlet oxygen and superoxide, in the heart, which caused transient vasodilatation, lasting up to $4 \mathrm{~min}$, followed by vasoconstriction (Kusama et al. 1989). In addition, singlet oxygen can initiate generation of hydroxyl radicals and, in the presence of NO, nitroxyl radicals as well.

We suspect that a significant part of the increase in hydroxyl radicals in brain tissue, using the photothrombosis model of ischemia, was related to the activity of Rose Bengal itself. There was a post irradiation increase in the concentration of hydroxyl radicals in the target hemisphere as well as the contralateral hemisphere. Additionally, after application of $\mathrm{RB}$, similar increases in the quantity of $\mathrm{OH}^{\bullet}$ radicals in the brains of animals that did not receive laser irradiation were also observed. DMPO by itself may also increase the amount of hydroxyl radicals (Nishizawa et al. 2004). However, in our experiments DMPO was also used in the naïve control group, however, naïve controls had hydroxyl radical concentrations significantly lower than the other groups treated with RB. Alternatively, it is possible that Rose Bengal can be partly activated by white light in the laboratory, and during circulation it can diffusely increase the amount of $\mathrm{OH}^{\bullet}$ radicals. To avoid the above mentioned issue, light intensity in the lab was kept at low levels and the retinas of the tested animals were checked for signs of ischemia prior to decapitation. Another interesting question is why there was no 
significant increase in $\mathrm{OH}^{\bullet}$ radicals in the laser irradiated hemisphere compared to the contralateral hemisphere. It is possible that the increase was so small that it was lost due to the general increase in hydroxyl radicals elicited by activated RB. Singlet oxygen is converted relatively easily to hydroxyl radicals, so it seems very unlikely that it was washed out of the affected area.

Nitric oxide (nitroxyl radical) is also highly reactive, but its half-life is somewhat longer and it crosses biological membranes freely. Physiological concentrations of nitric oxide are relatively low. Nitric oxide in the blood rapidly binds to heme to form methemoglobin, which is reduced by methemoglobin reductase to oxyhemoglobin and $\mathrm{NO}_{3}^{-}$. In ischemic tissue, nitric oxide acts on the nervous system both as a toxic as well as a protective agent (Liu et al. 2015, Moro et al. 2004), depending on the concentration. Changes in local blood flow related to focal ischemia are also the result of increased synthesis of NO by eNOS (endothelial nitric oxide synthase). NO production could be an attempt to start vasodilatation in the area of focal ischemia and signal for the opening of vascular anastomoses (Lapi and Colantuoni 2015). Changes in blood circulation in injured areas could be related to increased activity of eNOS. In addition the beginning of the inflammatory reaction has to be taken into consideration. This means that polymorphonuclear leukocytes (PMN) are attracted to the lesion, where they release iNOS (inducible nitric oxide synthase) into the area of the lesion. Nitric oxide is then secreted as an immune response agent. Ischemic necrosis causes PMNs to exit into tissues, which leads to their activation and a subsequent oxidation burst related to iNOS activity. The first PMNs arrive in the lesion area 30 to $60 \mathrm{~min}$ after the initiation of ischemia. The maximum number of PMNs, however, requires about 48 hours (Garcia et al. 1994). iNOS is also present in glial cells and as such would also play a role in the observed increase $\mathrm{NO}^{\bullet}$ radicals in the affected hemisphere. Increased generation of nitric oxide would also contribute to the reperfusion injury following ischemia. It can react with superoxide to produce damaging oxidants. In the present experiment it was assumed that the increased $\mathrm{NO}^{\bullet}$ production was mainly due to a reduction in blood flow and thereafter it was due to the increased activity of eNOS.

An excitotoxic release of glutamate after ischemia is also known to contribute to brain damage through extreme activation of nNOS (neuronal nitric oxide synthase) and subsequent $\mathrm{NO}^{\bullet}$ production (Moro et al. 2004). In the hemisphere contralateral to the ischemia hemisphere, the observed increase in $\mathrm{NO}^{\bullet}$ could have been caused by a similar increase in ischemia-induced glutamatergic activity (Duchemin et al. 2012). We must take into account that the increased local production of NO could be related to its production in neurons and glial cells. Nitric oxide and superoxide anion react to generate peroxynitrite and peroxynitrite initiates fibrinogen nitrotyrosination. Nitrotryrosinated fibrinogen impairs thrombolysis and is neurotoxic in ischemic brain tissue (Ill-Raga et al. 2015). Distant changes in blood flow occurring during lesion formation (diaschisis) are also probably involved in the rise of $\mathrm{NO}^{\bullet}$ in the contralateral hemisphere.

\section{Conclusions}

We observed significant increases in the number of nitroxyl radicals in the brain hemispheres with ischemic lesions. Although, the model of ischemia used, which involved application of Rose Bengal, did not allow us to determine with certainty a relationship between ischemia and an increase in the number of hydroxyl radicals. In part, a diffuse increase in hydroxyl radicals could have been caused by the slower degradation of hydroxyl radicals compared to nitroxyl radicals. Nevertheless, the results suggest that acute application of antioxidants could be beneficial in cases of focal ischemia of the brain.

\section{Conflict of Interest}

There is no conflict of interest.

\section{Acknowledgements}

This study was supported by the Project of Science Fields Development at Charles University \#PRVOUK P34 and \#260168/SVV/2015.

\section{References}

ARMSTEAD WM, RILEY J, KIESSLING JW, CINES DB, HIGAZI AA: Novel plasminogen activator inhibitor-1derived peptide protects against impairment of cerebrovasodilation after photothrombosis through inhibition of JNK MAPK. Am J Physiol Regul Integr Comp Physiol 299: R480-R485, 2010. 
BIDMON HJ, KATO K, SCHLEICHER A, WITTE OW, ZILLES K: Transient increase of manganese-superoxide dismutase in remote brain areas after focal photothrombotic cortical lesion. Stroke 29: 203-210; discussion $211,1998$.

CHOI YS, CHO KO, KIM EJ, SUNG KW, KIM SY: Ischemic preconditioning in the rat hippocampus increases antioxidant activities but does not affect the level of hydroxyl radicals during subsequent severe ischemia. Exp Mol Med 39: 556-563, 2007.

DE FILIPPIS B, VALENTI D, DE BARI L, DE RASMO D, MUSTO M, FABBRI A, RICCERI L, FIORENTINI C, LAVIOLA G, VACCA RA: Mitochondrial free radical overproduction due to respiratory chain impairment in the brain of a mouse model of Rett syndrome: protective effect of CNF1. Free Radic Biol Med 83: 167-177, 2015.

DEYKUN K, POMETLOVA M, SCHUTOVA B, MARES J: Modulations of behavioral consequences of minor cortical ischemic lesion by application of free radicals scavengers. Gen Physiol Biophys 30: 263-270, 2011.

DUCHEMIN S, BOILY M, SADEKOVA N, GIROUARD H: The complex contribution of NOS interneurons in the physiology of cerebrovascular regulation. Front Neural Circuits 6: 51, 2012.

FORKER EL, LUXON BA: Albumin-mediated transport of rose bengal by perfused rat liver. Kinetics of the reaction at the cell surface. J Clin Invest 72: 1764-1771, 1983.

GARCIA JH, LIU KF, YOSHIDA Y, LIAN J, CHEN S, DEL ZOPPO GJ: Influx of leukocytes and platelets in an evolving brain infarct (Wistar rat). Am J Pathol 144: 188-199, 1994.

HOLEČEK V, ROKYTA R, STOPKA P, VLASÁK R: Singlet oxygen (1O2), its conversions and biological interactions. Cesk Fysiol 56: 154-159, 2007.

HUNG LM, HUANG JP, LIAO JM, YANG MH, LI DE, DAY YJ, HUANG SS: Insulin renders diabetic rats resistant to acute ischemic stroke by arresting nitric oxide reaction with superoxide to form peroxynitrite. $J$ Biomed Sci 21: 92, 2014.

ILL-RAGA G, PALOMER E, RAMOS-FERNANDEZ E, GUIX FX, BOSCH-MORATO M, GUIVERNAU B, TAJES M, VALLS-COMAMALA V, JIMENEZ-CONDE J, OIS A, PEREZ-ASENSIO F, REYES-NAVARRO M, CABALLO C, GIL-GOMEZ G, LOPEZ-VILCHEZ I, GALAN AM, ALAMEDA F, ESCOLAR G, OPAZO C, PLANAS AM, ET AL:: Fibrinogen nitrotyrosination after ischemic stroke impairs thrombolysis and promotes neuronal death. Biochim Biophys Acta 1852: 421-428, 2015.

JIMENEZ-ALTAYO F, CARACUEL L, PEREZ-ASENSIO FJ, MARTINEZ-REVELLES S, MESSEGUER A, PLANAS AM, VILA E: Participation of oxidative stress on rat middle cerebral artery changes induced by focal cerebral ischemia: beneficial effects of 3,4-dihydro-6-hydroxy-7-methoxy-2,2-dimethyl-1(2H)benzopyran (CR-6). J Pharmacol Exp Ther 331: 429-436, 2009.

KHAN SH, BAZIANY A, BANIGESH A, HEMMINGS SJ, SHUAIB A: Evaluation of an optimal temperature for brain storage in delayed 2,3,5-triphenyltetrazolium chloride staining. J Neurosci Methods 98: 43-47, 2000.

KONTOS HA: Oxygen radicals in cerebral ischemia: The 2001 Willis lecture. Stroke 32: 2712-2716, 2001.

KRYSL D, DEYKUN K, LAMBERT L, POKORNY J, MARES J: Perifocal and remote blood-brain barrier disruption in cortical photothrombotic ischemic lesion, its modulation by the choice of anesthesia. J Physiol Pharmacol 63: 127-132, 2012.

KUSAMA Y, BERNIER M, HEARSE DJ: Singlet oxygen-induced arrhythmias. Dose- and light-response studies for photoactivation of rose bengal in the rat heart. Circulation 80: 1432-1448, 1989.

LAPI D, COLANTUONI A: Remodeling of cerebral microcirculation after ischemia-reperfusion. J Vasc Res $\mathbf{5 2}$ 22-31, 2015.

LIU H, LI J, ZHAO F, WANG H, QU Y, MU D: Nitric oxide synthase in hypoxic or ischemic brain injury. Rev Neurosci 26: 105-117, 2015.

MARES J, STOPKA P, NOHEJLOVA K, ROKYTA R: Oxidative stress induced by epileptic seizure and its attenuation by melatonin. Physiol Res 62 (Suppl 1): S67-S74, 2013.

MATEJOVSKA I, BERNASKOVA K, KRYSL D, MARES J: Influence of melatonin pretreatment and preconditioning by hypobaric hypoxia on the development of cortical photothrombotic ischemic lesion. Physiol Res 57: 283-288, 2008. 
MORO MA, CARDENAS A, HURTADO O, LEZA JC, LIZASOAIN I: Role of nitric oxide after brain ischaemia. Cell Calcium 36: 265-275, 2004.

NELSON CW, WEI EP, POVLISHOCK JT, KONTOS HA, MOSKOWITZ MA: Oxygen radicals in cerebral ischemia. Am J Physiol 263: H1356-H1362, 1992.

NISHIZAWA C, TAKESHITA K, UEDA J, MIZUNO M, SUZUKI KT, OZAWA T: Hydroxyl radical generation caused by the reaction of singlet oxygen with a spin trap, DMPO, increases significantly in the presence of biological reductants. Free Radic Res 38: 385-392, 2004.

ROKYTA R, STOPKA P, KAFUNKOVA E. KRIZOVA J, FRICOVA J: The evaluation of nociceptive intensity by using free radicals, direct measurement by EPR method in the tail of anaesthetized rats. Neuro Endocrinol Lett 29: 1007-1014, 2008.

SCHOKNECHT K, PRAGER O, VAZANA U, KAMINTSKY L, HARHAUSEN D, ZILLE M, FIGGE L, CHASSIDIM Y, SCHELLENBERGER E, KOVACS R, HEINEMANN U, FRIEDMAN A: Monitoring stroke progression: in vivo imaging of cortical perfusion, blood-brain barrier permeability and cellular damage in the rat photothrombosis model. J Cereb Blood Flow Metab 34: 1791-1801, 2014.

SIESJO BK: Cell damage in the brain: a speculative synthesis. J Cereb Blood Flow Metab 1: 155-185, 1981.

SUN J, LI YZ, DING YH, WANG J, GENG J, YANG H, REN J, TANG JY, GAO J: Neuroprotective effects of gallic acid against hypoxia/reoxygenation-induced mitochondrial dysfunctions in vitro and cerebral ischemia/reperfusion injury in vivo. Brain Res 1589: 126-139, 2014.

TAO T, LIU Y, ZHANG J, XU Y, LI W, ZHAO M: Therapeutic hypercapnia improves functional recovery and attenuates injury via antiapoptotic mechanisms in a rat focal cerebral ischemia/reperfusion model. Brain Res 1533: 52-62, 2013.

UCHINO H, KURODA Y, MOROTA S, HIRABAYASHI G, ISHII N, SHIBASAKI F, IKEDA Y, HANSSON MJ, ELMER E: Probing the molecular mechanisms of neuronal degeneration: importance of mitochondrial dysfunction and calcineurin activation. $J$ Anesth 22: 253-262, 2008.

VALKO M, LEIBFRITZ D, MONCOL J, CRONIN MT, MAZUR M, TELSER J: Free radicals and antioxidants in normal physiological functions and human disease. Int J Biochem Cell Biol 39: 44-84, 2007.

WATSON BD, DIETRICH WD, BUSTO R, WACHTEL MS, GINSBERG MD: Induction of reproducible brain infarction by photochemically initiated thrombosis: Ann Neurol 17: 497-504, 1985.

WATSON BD, PRADO R, VELOSO A, BRUNSCHWIG JP, DIETRICH WD: Cerebral blood flow restoration and reperfusion injury after ultraviolet laser-facilitated middle cerebral artery recanalization in rat thrombotic stroke. Stroke 33: 428-434, 2002. 